\title{
From open resources to educational opportunity
}

\author{
M. S. Vijay Kumar* \\ Massachusetts Institute of Technology, USA
}

Since MIT's bold announcement of the OpenCourseWare initiative in 2001, the content of over 700 of its courses have been published on the Web and made available for free to the world. Important infrastructure initiatives have also been launched recently with a view to enabling the sustainable implementation of these educational programmes, through strengthening organizational capacity as well as through building open, standards-based technology. Each of these initiatives point to a rich palette of transformational possibilities for education; together with the growing open source movement, they offer glimpses of a sustainable ecology of substantial and quality educational resources. This discussion piece will highlight some of the educational opportunity presented by MIT's current information technology-enabled educational agenda and related initiatives, along with their strategic underpinnings and implications. It will address various dimensions of their impact on the form and function of education. It will examine how these ambitious programmes achieve a vision characterized by an abundance of sustainable, transformative educational opportunities, not merely pervasive technology.

\section{The Internet, open content and active learning}

OpenCourseWare looks counter-intuitive in a market-driven world. It goes against the grain of current material values. But it really is consistent with what I believe is the best about MIT. It is innovative. It expresses our belief in the way education can be advancedby constantly widening access to information and by inspiring others to participate. (Charles M. Vest, President Emiritus, MIT, September 2001)

MIT's announcement to the world in April 2001, that it would be posting the content of some 2,000 MIT courses on the Web, is certainly a visible and voluble signal of the Institute's intent to extend technology-enabled opportunities to expand educational access and quality. No educational institution has ever proposed anything as revolutionary, or as daunting.

\footnotetext{
* Massachusetts Institute of Technology, 211 Massachusetts Avenue, Room N42-253, Cambridge, MA, USA. Email: vkumar@MIT.EDU
} 
The idea behind MIT OpenCourseWare (OCW) (http://web.mit.edu/oki) is to make course materials that are used in the teaching of almost all undergraduate and graduate subjects at MIT available on the Web free of charge, to any user anywhere in the world. OCW is a large-scale, Web-based electronic publishing initiative funded jointly by the William and Flora Hewlett Foundation, the Andrew W. Mellon Foundation and MIT. Its goals are:

1. to provide free, searchable, coherent access to MIT's course materials for educators in the non-profit sector, students and individual learners around the world; and

2. to create an efficient, standards-based model that other universities may emulate to publish their own course materials. Extensive metadata tagging, launching a comprehensive ongoing evaluation process, developing and enhancing our content management and publishing technologies, and evolving our internal staffing and workflow are important elements of this process.

MIT OCW will advance technology-enhanced education at MIT, and will serve as a model for university dissemination of knowledge in the Internet age. This venture continues the tradition at MIT of open dissemination of educational materials, philosophy and modes of thought, and will help lead to fundamental changes in the way colleges and universities utilize the Internet as a vehicle for education (Diamond, 2003). According to Miyagawa, an MIT professor of linguistics, 'OCW reflects the idea that, as scholars and teachers, we wish to share freely the knowledge we generate through our research and teaching'. He goes on to state that 'While MIT may be better known for our research, with OCW, we wish to showcase the quality of our teaching'.

As of June 2005, 1,100 courses in areas ranging from Computer Science to Political Science have been published. The positive reaction and global impact of the initiative is evidenced through the extensive visits to the OCW site from people in countries across the world and also the comments on the value of the materials (http://ocw.mit.edu/OcwWeb/Global/AboutOCW/worldreaction.htm).

While MIT's initial efforts focused on meeting the original publishing target, it has also looked at ways to extend OCW's reach through exploring translation efforts (such as Spanish), through tools to facilitate the use and through the engagement of like-minded institutions.

OCW has important implications for meeting the needs of education beyond providing extensive access to course content. OCW presents a snapshot of the transactions in a course - the lectures, assignments, and discussions, along with the structural relationship between these entities - thereby providing a view of the practices and pedagogies employed, and hence a useful model for educators everywhere.

While OCW has been the keynote, it has not been an isolated event in MIT's agenda to employ technology for educational transformation. Projects, such as those supported by the I-Campus initiative (an alliance between MIT and Microsoft Research) as well as the MIT Council on Educational Technology (MITCET), have led to innovations for developing content, tools and pedagogy with the potential to 
significantly impact the form and function of educational practice. The following examples illustrate this.

\section{Transforming field studies}

MIT students from the Environmental Studies programme have been traveling in Australia and New Zealand collecting data from soil and water samples through environmental and geo-positional sensors, storing the data, making computations in the field based on the data, and displaying the data. This group of students was part of the ENVIT project at MIT, whose goal was to create Mobile Field Data Collection Software for the Environmental Professional. The central piece of technology employed here is a Personal Digital Assistant integrated with other hardware and software modified for mobility; namely, Teletype GPS sensors, Hydrolab multi-parameter water quality probes, ESRI ArcPad Mobil GIS and Windows CE development using embedded Visual Basic, $\mathrm{C}++$ and Access. This innovation has moved field sampling and measurements (still largely dependent upon pencil-and-paper field notebooks) to a new level of accuracy and efficiency. It has wonderful implications for mobile learners, field engineers and scientists who have hitherto lacked the appropriate technology to carry out their work in an efficient manner.

\section{iLab-first-hand experience over the Internet}

Over the past two years, students at globally distributed locations such as institutions in Singapore, which are part of MIT's Singapore MIT Alliance programme, as well as Sweden among others, were able to use laboratory equipment located at MIT. Specifically, these students used network analyzer equipment employed in microelectronics courses for various experiments, such as measuring characterizations of transistors.

The iLab project (http://swiss.csail.mit.edu/projects/icampus/projects/ilab.html) that makes this possible enables access to these instruments through a Web interface. Through iLab it is possible to deliver hands-on experimentation to students anywhere, at anytime. In addition to Microelectronics, laboratories and experimental set-ups that are being Web-enabled include Reactors for Polymerization, Heat Exchangers and Shake Tables for seismic measurements. The iLab ambition is to create the framework to extend access beyond these specific experiments to a variety of remote, geographically dispersed laboratories.

\section{Educational value}

A significant characteristic of the technological innovations described here is that they support active learning and first-hand experience, both important elements of the MIT's educational programmes, in flexible, location-independent and contextually relevant ways that add richness to the learning experience. Another notable example of promoting active learning is Technology Enabled Active Learning, which involves transforming large lecture courses to active, collaborative studio-based learning for physics. 
An important educational characteristic of these technological innovations is also that they induce important proximities between learners, their peers and instructors as well as the community. The net result is an increased interaction of the learner with the content, context and community.

\section{The educational promise and strategic underpinnings}

The promise of new technologies in terms of new pedagogy, abundant content and new clientele for education are numerous and seductive. However, understanding and exploiting these opportunities requires educational institutions to have a 'strategic focus'; that is, they should select a limited set of opportunities to explore and should pursue those opportunities in depth. Institutions must identify specific targets of opportunity and need and particular areas of intrinsic value and potential uniqueness (Kumar, 2000).

MIT'S approach leading to the launch of these innovations reflects (at least in hindsight) such a strategic focus. Starting in 1999, the MITCET undertook a six-month study looking at how MIT should respond to the opportunity presented by emerging technology; in particular, the Internet. The visioning exercise led to a variety of potential scenarios of how MIT could position itself. The starting point of this exercise was a reflection on and articulation of the unique aspects of the MIT educational experience, to answer the question: 'What is MIT's educational value proposition?' The MITCET identified that a central dimension of MIT's educational value was the high bandwidth of interaction between excellent students and excellent faculty. Another was the importance of first-hand experience in the educational process. MIT's educational technology strategy therefore was to launch experiments to: understand how information technology could amplify these value dimensions, extend it to other communities not typically served by MIT, and address existing obstacles to achieving this value in current practice. MIT's educational technology initiatives over the past few years reflect this strategy and address the inherent opportunities and challenges. The OCW idea, that the best way to advance MIT's fundamental mission and exploit the Internet would be to put all MIT's course materials on the Web, open to everyone, and free, was, in retrospect, a logical conclusion to this strategic exercise.

Both iLabs, which builds on the values of hands-on experience in MIT education, and Technology Enabled Active Learning, which addresses the problem of large lectures through studio-based learning in small collaborative groups, also reflect how the educational technology strategy was in alignment with the educational value proposition. The strategizing exercise by the MITCET set the stage for a series of large-scale educational experiments to promote innovative teaching and learning, as well as for the creation of an educational commons.

\section{Infrastructure for sustainability}

Important infrastructure initiatives were also launched with a view to enabling the sustainable implementation of these educational programmes, through building 
technology platforms and facilities as well as through strengthening organizational capacity and alignment. In the area of building technology platforms, three initiatives are important to mention in the context of this discussion: Stellar, MIT's Course Management System; dSpace, a project to develop a digital repository for educational materials; and the Open Knowledge Initiative (OKI), for developing an open architecture to support the portability and sustainability of educational applications and their easily integration into campus infrastructures. The long-term goals of these infrastructure efforts are to link the MIT community worldwide, and to provide easy access to the full range of MIT's intellectual life and resources (library materials, research facilities, colloquia, etc.). MIT's infrastructure will make it easy to communicate, follow coursework and collaborate online.

\section{Porting, sharing and integration through the OKI}

The OKI provides educational projects with a general framework that allows technology innovation to be safely incorporated into live learning environments. Innovators' work can also be easily shared with users and developers at other institutions that support the OKI framework. For instance, OKI will enable MIT, the University of Michigan and Indiana University to offer leverage to their development efforts to share tool and applications in the evolution of their collaborative Sakai platform (www.sakaiproject.edu). It will also enable institutions to provide a rich suite of educational functionality such as for assessment and concept mapping as well as for searching and presenting image collections. The Visual Understanding Environment (http://vue.tccs.tufts.edu/) project at Tufts University and the Narravision application being developed at MIT, to support the Visualizing Cultures class course, are examples. These tools use software provided by the OKI that allows several repositories to be accessed simultaneously and offer leverages to the local institute's infrastructure. OKI enables research and development efforts to concentrate on core functionality, rather than spending time and money building simulated environments or managing complex system integrations.

So how does OKI do this? OKI started with a somewhat modest ambition: to develop extensible and customizable applications that provide Learning Management Systems functionality. Early in the project, its leaders recognized that open, extensible and clearly defined architectural specifications are critical to realizing this ambition, as well as for other educational applications. The interface methods defined by OKI support the ongoing integration of three general categories of software:

- Learning applications ranging from individual quizzing, authoring and collaboration tools to suites of such tools that include course management and learning management capabilities.

- Central administrative systems such as student information, human resources and directory management.

- Academic systems including library information systems and digital repositories of research and educational materials. 
At the time of launching OKI we observed that while existing learning management systems were serving a very important function, in that they had created a very low barrier to entry for universities mounting course materials, they presented a high barrier to exit. Technical design aspects limited the portability and interoperability of learning resources and consequently inhibited the kind of flexibility that leads to greater use and sharing of learning materials. For example, the tight coupling of the user interface to learning components (as in a monolithic learning system) constrains the ability for resources to be used in different educational settings and contexts. Typically the solutions available were unsuitable because they were all-in-one packages with components offering a single level of functionality designed for widespread use.

OKI embraces a component-based approach that relies on loose, lightweight, but well-defined contracts to enable links to common infrastructure services. OKI provides specifications for interfaces among components of a learning technology environment. The intent is to make it easier for campus and commercial developers to produce software that will work in a range of higher education infrastructures to satisfy diverse educational needs. By providing a stable, scalable base that supports the flexibility needed by higher education, OKI offers an approach that may help us to produce and share high-quality courseware and to construct enterprise applications more cost-effectively and more efficiently, as learning technology is increasingly integrated into the education process.

The OKI has produced and made available as Open Source, a series of Open Service Interface Definitions informed by a broad architectural view of the educational technology landscape (http://www.okiproject.org).

OKI's work in the educational systems is by no means the first. Initial work in the interoperability area such as that of the IMS Global Consortium led to some common definitions and standards for data interchange (Sharable Content Object Reference Model). These are useful for copying content from one system to another. They primarily address the encoding of data for exchange among cooperating systems and address issues such as metadata and learning design that address the semantics of learning content. However, to get more complete real-time integration, service specifications are required in addition to data specifications.

$\mathrm{OKI}$ is still only a step in the path of component-based approaches to design and the evolution of global specifications and standards, crucial for advancing the use and interoperability of learning resources.

OKI's Open Service Interface Definitions are available in open source mode to facilitate the large-scale adoption of this architectural model. This will allow institutions to easily take advantage of new technology and new learning management components as they become available. It will also allow components to be updated individually without destabilizing the overall environment.

\section{The end game: ecology of open educational opportunity}

MIT's approach for developing its educational technology strategy urges careful consideration of the core values of an institution and reflection of its value proposition. 
Sustainability has been a key theme in MIT's efforts, and ensuring alignment with institutional and educational values was seen as a necessary first-step in this direction. Selecting a limited set of educational experiments was an important aspect of our efforts, as was designing an infrastructure to enable the success and durability of these experiments. Our efforts toward this end had to also take into account some 'givens' of the educational ecosystem:

- Educational value is derived in multiple ways and modalities, requiring a heterogeneous set of tools.

- The technologies on which we build our infrastructure will necessarily change.

- The implementation of educational applications of scale and substance requires integration with the existing infrastructure and enterprise.

The end goal is to be able to ensure that the quality educational content and tools that are being created through innovative uses of technology at MIT elsewhere can indeed be leveraged to substantively impact educational opportunity and transformation in its form and function.

In the period ahead we will be learning from the implementation of our efforts. The feedback we receive about the dynamics of adoption including contextual considerations will influence ongoing development of our initiatives and help deliver the promise of advancing learning through technology and progress in education.

\section{References}

Diamond, D. (2003) MIT everyware, Wired Magazine, 11 September. Available online at: http:// www.wired.com/wired/archive/11.09/mit_pr.html (accessed 20 September 2003).

Kumar, V. (2000) Choosing the right track for IT's transformation of teaching and learning, viewpoints, EDUCAUSE Review, June.

Long, P. D., Merriman, J., Kumar, V. \& Walker, E. (2003) Specifications and common services for interoperability: new landscape for learning technology, Syllabus Magazine, 1 July. Available online at: http://www.syllabus.com/article.asp?id=78 (accessed 20 September 2003).

Merriman, J. (2002) What is OKI?, white paper. Available online at: http://web.mit.edu/oki.

Merriman, J. \& Kumar, V. (2001) Building 'open' frameworks for education, new horizons, EDUCAUSE Review, 36(6).

Tansey, F. (2003) The standard bearers close ranks, syllabus. Available online at: http:// www.syllabus.com/article.asp?id=7359 (accessed 20 September 2003). 